\title{
O RACISMO E A HIPERSEXUALIZAÇÃO DA MULHER NEGRA EM CADERNO DE MEMÓRIAS COLONIAIS DE ISABELA FIGUEIREDO
}

\author{
Cinthia da Silva Belonia ${ }^{1}$
}

Resumo: No romance Caderno de memórias coloniais, da escritora portuguesa Isabela Figueiredo, o leitor pode observar a violência com que eram tratados os negros de Moçambique durante o período colonial dos anos 60-70. A sociedade local é extremamente racializada, sendo a hipersexualização da mulher negra o principal assunto nas conversas entre as mulheres brancas. Essa hipersexualização será analisada com base no livro Pele negra Máscaras brancas do psiquiatra martinicano Frantz Fanon. Para melhor analisar o racismo que tem o negro como mão de obra barata e a mulher negra como portadora de uma sexualidade exagerada, convocaremos também os autores Sergio Costa e Kwame Anthony Appiah.

Palavras-chave: racismo, mulher, hipersexualização, Isabela Figueiredo.

Abstract: At the novel Caderno de memórias coloniais, of the Portuguese writer Isabela Figueiredo, the reader can observe the violence that the Mozambican black people suffered during the colonial period at the 60 's and 70 's. The local society is very racialized, and the over-sexualization of the black women was the main subject of the conversation between the white women. This over-sexualization will be analyzed based on the book Pele negra Máscaras brancas of the Martinican psychiatrist Frantz Fanon. To analyze the racism of the cheap labor of the black people and the exaggerated sexuality of the black women, we will call the authors Sergio Costa and Kwame Anthony Appiah.

Keywords: racism, women, over-sexualization, Isabela Figueiredo.

1 Graduada em Letras-Português pela Universidade Federal do Espírito Santo; Mestre em Literatura Hispano-americana pela Universidade Federal Fluminense; Doutoranda em Literatura Comparada na Universidade Federal Fluminense. 
Este artigo analisa o racismo e a condição da mulher negra em Moçambique no período colonial a partir da narrativa de Isabela Figueiredo, uma escritora portuguesa, nascida em Moçambique e retornada ${ }^{2}$ de lá ainda criança. Caderno de memórias coloniais (2010) narra a infância da personagem narradora em Moçambique, o racismo por parte dos colonos portugueses e do pai, que, para ela, era quem lhe "trazia o mundo". Em entrevista no final do livro, Isabela Figueiredo diz que esse livro é uma espécie de ajuste de contas com o pai, uma forma de absolvê-lo, mas também um ajuste de contas com os outros retornados vivos e com os portugueses que os maltrataram quando estes chegaram a Portugal sem saber que eles já haviam pagado um preço alto ainda na colônia.

Caderno de memórias coloniais é a memória a partir do olhar de uma criança sobre o colonialismo português personificado na figura do pai. O livro alinha-se à geração dos netos que Salazar não teve: os filhos da Guerra Colonial, da ditadura, dos retornados, crianças com uma memória própria dos eventos que levaram ao fim o império português em África, ou a pós memória (aqueles que não têm memória própria desses eventos, mas cresceram ouvindo as histórias das quais não foram testemunhas).

Caderno de memórias coloniais nos mostra, também, a violência bruta cotidiana dos brancos contra os negros: o racismo de cor, personificado na hipersexualização da mulher negra e na infantilização do homem negro.

\section{"Os brancos iam às pretas"}

A mulher ocupou sempre uma posição subordinada, sendo privada, na organização patriarcal, "de sua própria História e das histórias que modelizam sua própria história" (GERRA apud PADILHA, 2007, p.472). A sociedade de Maputo apresentada no livro é extremamente machista e racializada. O espaço da mulher é o privado, sempre dentro de casa cuidando dos filhos e dos afazeres domésticos. Seu lazer cotidiano se resume em conversar com outras mulheres vizinhas, sendo o assunto da mulher branca o corpo da mulher negra, e este era reduzido ao sexo:

Os brancos iam às pretas. [...] /As pretas tinham a cona larga, mas elas diziam as partes baixas ou as vergonhas ou a badalhoca. As pretas tinham a cona larga e essa era a explicação para parirem como pariram, de borco, todas viradas para o chão, onde quer que fosse, como os animais. A cona era larga. A das brancas não, era estreita, porque as brancas não eram umas cadelas fáceis, porque à cona sagrada das brancas só lá tinham chegado o do marido, e pouco, e com dificuldade, que elas eram muito estreitas, portanto muito sérias, e convinha que uma soubesse disso das outras. (FIGUEIREDO, 2010, p. 13)

2 Retornado(a) é a forma como os portugueses foram designados ao voltar das ex-colônias africanas para Portugal ao fim do Império Colonial. Assim também foram chamados seus filhos, nascidos em África, ao chegarem, pela primeira vez, à antiga metrópole. 
Comumente as negras que se relacionavam com os brancos engravidavam. No entanto, não cobravam deles a paternidade do filho, pois não tinham esse direito. Ninguém acreditaria nelas: "Como é que uma negra descalça, de teta pendurada, [...] sem bilhete de identidade, sem carteira de assimilada, poderia provar que o patrão era o pai da criança” (FIGUEIREDO, 2010, p. 14). Elas nada faziam por saber que poderiam apanhar. Muitos desses mulatos jamais conheciam o pai. As pretas se deitavam com o branco "a bem ou a mal", que em seguida iam para suas honestas casas de família. Segundo Spivak (1997), em Pode o subalterno falar? "a mulher subalterna continuará muda como sempre esteve" (SPIVAK, 1997, p. 86). $\mathrm{Na}$ condição de sujeito subalterno Spivak diz que a mulher está envolvida ainda mais, pois é pobre, negra e mulher.

Um branco poderia casar com uma negra e esta ascender socialmente, por respeito ao branco, e sempre com ressalvas. No entanto, uma mulher branca jamais poderia assumir um relacionamento com um homem negro, seria uma proscrição social, pois este nunca seria suficientemente civilizado: "um preto nunca poderia tratar bem uma branca, como ela merecia. Era outra gente. Outra cultura. Uns cães" (FIGUEIREDO, 2010, p. 15).

A sexualidade do negro é tema de conversa entre as mulheres brancas:

[...] quando se juntavam, falavam das cabras das pretas e das facilidades com que tinham filhos uns atrás dos outros, porque eram muito abertas, e também gostavam... e aludiam sub-repticiamente ao que se dizia serem as características dos órgãos sexuais masculinos do negro e voltavam ao tema de que as negras gostavam de fazer aquilo... [...]/ Uma branca não admitia que gostasse de foder, mesmo que gostasse. E não admitir era uma garantia de seriedade para o marido, para a imaculada sociedade toda. As negras fodiam, essas sim, com todos e mais alguns, com os negros e os maridos das brancas, por gorjeta, certamente, por comida, ou por medo. E algumas talvez gostassem, e guinchassem, porque as negras eram animais e podiam guinchar. Mas, sobretudo, porque as negras autorizavam-se a si próprias a guinchar, a abrir as pernas, a ser largas. (FIGUEIREDO, 2010, p. 22-21)

Mesmo sabendo da possibilidade de um estupro do branco contra a negra, a branca não se penalizava, como se a mulher negra fosse culpada pelo que lhe acontecia, pois eram animais e viviam com as pernas abertas. A mulher negra é subalternizada, e "o subalterno como um sujeito feminino não pode ser ouvido ou lido" (SPIVAK, 1997, p. 124), porque não há um valor atribuído à mulher. Spivak (1997) conclui seu pensamento dizendo que "o subalterno não pode falar. Não há valor algum atribuído à 'mulher' como um item respeitoso nas listas de prioridades globais" (SPIVAK, 1997, p. 126).

Nenhum branco queria ser servido por outro branco ou ter empregados brancos, pois sairia mais caro. Ter empregados negros era mais barato. O negro não tinha o mesmo valor que o branco e podia apanhar do patrão para que fizesse o trabalho bem feito e não reclamasse. Um branco só servia para chefe e mandar trabalhar o empregado negro que era sempre preguiçoso. A mulher do negro era mais respeitada, porque muitas vezes trabalhava enquanto o marido descansava. Eram mais respeitadas pelos patrões. "O negro estava abaixo de tudo. Não tinha direitos. Teria os da caridade, e se a merecesse. Se fosse humilde. / Esta 
era a ordem natural e inquestionável das relações: preto servia o branco, e branco mandava no preto" (FIGUEIREDO, 2010, p. 24).

Vale ressaltar que o racismo presente no romance não pertence ao pensamento da narradora. Trata-se, na verdade, da reprodução das conversar ouvidas por ela dos demais colonos de Lourenço Marques. Podemos observar aqui um exemplo de como a diferença racial era vista por essa sociedade:

Um branco e um preto não eram apenas de raças diferentes. A distância entre brancos e pretos era equivalente à que existe entre diferentes espécies. Eles eram pretos, animais. Nós éramos brancos, éramos pessoas, seres racionais. Eles trabalhavam para o presente, para a aguardente-de-cana do "dia de hoje"; nós, para poder pagar a melhor urna, a melhor cerimónia no dia do nosso funeral. (FIGUEIREDO, 2010, p. 35)

Cada um trabalhava para conquistar suas prioridades. A prioridade imediatista do negro era ridicularizada pelo branco, pois este pensava no futuro, mesmo que o futuro fosse a morte.

O psiquiatra martinicano Frantz Fanon faz uma análise psicológica acerca do negro em Pele negra Máscaras brancas, um dos temas abordados é a sexualidade da mulher e do homem negro. Segundo ele, as negras se relacionavam com os brancos pela necessidade de embranquecer a raça. Embranquecer é salvar a raça, não para preservar "a originalidade da porção do mundo onde elas cresceram”, mas para assegurar sua brancura. Qualquer antilhana (contexto geográfico e cultural de Frantz Fanon) sabe disso e terá uma preocupação em escolher seus pares, para que sejam brancos podendo gerar filhos mestiços. Até que seus descendentes sejam brancos. "As pessoas costumam pedir desculpas quando ousam propor um amor negro a uma branca" (FANON, 2008, p. 63). As mulheres de cor vivem assombradas pelo grande sonho de se casar com um branco e europeu, pois precisam de um homem branco, e nada mais que isso. Porque a negra se sente inferior, então aspira ser admitida no mundo branco, para passar da casta dos escravos para a casta dos senhores.

Sobre a assimilação, Fanon menciona a linguagem. Ao adotar a língua portuguesa o nativo moçambicano assimila o mundo do branco: "Um homem que possui a linguagem possui, em contrapartida, o mundo que essa linguagem expressa e que lhe é implícito" (FANON, 2008, p. 34). Quanto mais o colonizado assimila os valores culturais da metrópole, mais ele se afasta da sua selva, rejeita sua negridão, seu mato e mais branco será. Um negro poderia ser assimilado, mas nunca seria como um branco:

Era absolutamente necessário ensinar os pretos a trabalhar, para seu próprio bem. Para evoluírem através do reconhecimento do valor do trabalho. Trabalhando, poderiam ganhar dinheiro, e com o dinheiro poderiam prosperar, desde que prosperassem como negros. Poderia deixar de ter uma palhota e construir uma casa de cimento com telhado de zinco. Poderiam calçar sapatos e mandar os filhos à escola para aprender ofícios que fossem úteis aos brancos. Havia muito a fazer pelo homem negro, cuja natureza animal deveria ser anulada - para seu bem. (FIGUEIREDO, 2010, p. 51) 
Por mais que um negro pudesse e tentasse mudar de vida, nunca lhe seria permitido ocupar o lugar do branco. Ser assimilado significa não ser português.

Frantz Fanon diz que devemos entender, de uma vez por todas, que uma sociedade é racista ou não é. Dizer que uma sociedade é menos racista que outra ou que o racismo é obra do subalterno, não comprometendo a elite, é próprio de homens incapazes de pensar corretamente. "É utópico procurar saber em que um comportamento desumano se diferencia de outro comportamento desumano" (FANON, 2008, p. 85). Todas as formas de exploração se parecem, o racismo colonial não difere de outro racismo.

O filósofo e escritor anglo-ganês Kwame Anthony Appiah, em Na casa de meu pai: A África na filosofia da cultura, escreve que há muitas doutrinas distintas que cabem o termo "racismo". Ele aborda três dessas doutrinas que nos ajudam a entender os diferentes tipos de racismos: racialismo, racismo extrínseco e racismo intrínseco. No racialismo existem características hereditárias, possuídas por membros da mesma espécie permitindo dividi-los em um pequeno conjunto de raças, dessa forma os membros desse grupo compartilham entre si certos traços e tendências que não têm em comum com nenhuma outra raça. "O racialismo está no cerne das tentativas do século XIX de desenvolver uma ciência da diferença racial, mas parece ter despertado também a crença dos outros [...] que não tinham nenhum interesse em elaborar teorias científicas" (APPIAH, 1997, p. 33). Sobre o racismo extrínseco, Appiah escreve que a base da discriminação entre os povos é a crença em que pessoas de diferentes raças diferem em aspectos (honestidade, coragem ou inteligência) que justificam o tratamento diferenciado.

Segundo Appiah, os racistas intrínsecos estabelecem diferenças morais entre povos de diferentes raças, pois acreditam que cada raça tenha um status moral diferente:

[...] o racista intrínseco sustenta que o simples fato de ser de uma mesma raça é razão suficiente para preferir uma pessoa a outra. Para um racista intrínseco, nenhuma quantidade de provas de que um membro de outra raça é capaz de realizações morais, intelectuais ou culturais, ou de que tem características que, em membros de sua própria raça, haveriam de torná-lo admirável ou atraente, serve de base para tratar essa pessoa como ele trataria os membros similarmente dotados de sua própria raça. (APPIAH, 1997, p. 35)

Appiah acredita que ambos os racismos deveriam ser esquecidos. O racismo intrínseco é um erro moral, pois defende a ideia de que por pertencer a uma mesma "raça" deve-se tratar um "semelhante" melhor que uma pessoa de outra "raça". O racismo extrínseco implica falsas crenças, pois acredita-se que a essência racial implica em qualidades moralmente relevantes e essas diferenças justificariam o tratamento diferencial entre as mesmas.

Para Appiah a raça é uma ilusão. Ele cita Du Bois que argumenta que raça não é um conceito científico/biológico, mas sócio histórico. É possível que a história tenha nos tornado o que somos, mas essa história foi escolhida no passado, mesmo que antes do nosso nascimento, o que torna nossa história sendo sempre uma escolha. É o racista quem cria o inferiorizado. Ele não permite que o subalterno tente se igualar ao europeu. Sempre vão lembrar o colono qual é o seu lugar, para dessa forma continuar a dominá-lo. 
O professor Sérgio Costa, em Dois Atlânticos: Teoria social, antirracismo, cosmopolitismo, faz um breve resumo sobre o racismo:

O racismo corresponde à suposição de uma hierarquia quantitativa entre seres humanos, os quais são classificados em diferentes grupos imaginários, a partir de marcas corporais arbitrariamente selecionadas. Essa hierarquização apresenta tanto consequências socioeconômicas quanto político-culturais. As primeiras dizem respeito ao surgimento de uma estrutura de oportunidades desigual, de tal sorte que aqueles a quem se atribui uma posição inferior na hierarquia racial imaginada são sistematicamente desfavorecidos na competição social, cabendo-lhes os piores postos de trabalhos, salários proporcionalmente menores, dificuldades de acesso ao sistema de formação escolar e profissional, etc. A dimensão cultural do racismo se expressa no cotidiano, através de formas de comportamento (escolhas matrimoniais, tratamento pessoal discriminatório), rituais (insulto racista, humilhações), assim como através da marginalização social e espacial. (COSTA, 2006, p. 11)

Costa também escreve sobre a política da representação. Ora o negro é representado com o desenvolvimento moral e intelectual limitado, sendo infantilizado, ora cultiva-se a fantasia do negro hipersexualizado (oversexed). A "cona larga" citada em Caderno de memórias coloniais é, ainda hoje, uma forma da representação das mulheres negras ao redor do mundo. O negro neste livro é representado como os negros costumam ser em outras narrativas, reforçando sempre a imagem de indivíduos inferiores, irracionais, animalescos, infantilizados e hipersexualizados.

\section{Conclusão}

Para concluir, o professor Sérgio Costa, em Dois Atlânticos: Teoria social, antirracismo, cosmopolitismo, faz um breve resumo sobre o racismo:

O racismo corresponde à suposição de uma hierarquia quantitativa entre seres humanos, os quais são classificados em diferentes grupos imaginários, a partir de marcas corporais arbitrariamente selecionadas. Essa hierarquização apresenta tanto consequências socioeconômicas quanto político-culturais. As primeiras dizem respeito ao surgimento de uma estrutura de oportunidades desigual, de tal sorte que aqueles a quem se atribui uma posição inferior na hierarquia racial imaginada são sistematicamente desfavorecidos na competição social, cabendo-lhes os piores postos de trabalhos, salários proporcionalmente menores, dificuldades de acesso ao sistema de formação escolar e profissional, etc. A dimensão cultural do racismo se expressa no cotidiano, através de formas de comportamento (escolhas matrimoniais, tratamento pessoal discriminatório), rituais (insulto racista, humilhações), assim como através da marginalização social e espacial. (COSTA, 2006, p. 11) 
Costa também escreve sobre a política da representação. Ora o negro é representado com o desenvolvimento moral e intelectual limitado, sendo infantilizado, ora cultiva-se a fantasia do negro hipersexualizado (oversexed). A “cona larga" citada em Caderno de memórias coloniais é, ainda hoje, uma forma da representação das mulheres negras ao redor do mundo. O negro neste livro é representado como os negros costumam ser em outras narrativas, reforçando sempre a imagem de indivíduos inferiores, irracionais, animalescos, infantilizados e hipersexualizados.

\section{Referências bibliográficas}

APIAH, Kwame Anthony. Na casa de meu pai: a África na filosofia da cultura. Tradução de Vera Ribeiro. Revisão da tradução por Fernando Rosa Ribeiro. Rio de Janeiro: Contraponto, 1997.

COSTA, Sérgio. Dois Atlânticos: teoria social, anti-racismo, cosmopolitismo. Belo Horizonte: Editora UFMG, 2006.

FANON, Frantz. Pele negra máscaras brancas. Tradução de Renato da Silveira. Salvador: EDUFBA, 2008.

FIGUEIREDO, Isabela. Caderno de memórias coloniais. 4. ed. Coimbra: Angelus Novus, 2010.

PADILHA, Laura C. "Bordejando a margem (Escrita feminina, cânone africano e encenação de diferenças)". In: A MULHER EM ÁFRICA Vozes de uma margem sempre presente. Lisboa: Edições Colibri, 2007.

SPIVAK, Gayatri C. Pode o subalterno falar? Belo Horizonte: Editora UFMG, 2010. 
